\title{
Research Paper \\ Compiling and Evaluating Educational Package of Spiritual Skills for University Students
}

\author{
Jafar Bolhari ${ }^{1}$ (i), ${ }^{*}$ Masoomeh Mohsenikabir ${ }^{2}$ 두
}

1. Psychiatrist, Spiritual Health Research Center, School of Behavioral Sciences and Mental Health, Iran University of Medical Sciences, Tehran, Iran. 2. Ph.D. Student in Psychology of Health, Department of Health Psychology, Faculty of Psychology, Karaj Branch, Islamic Azad University, Karaj, Iran.

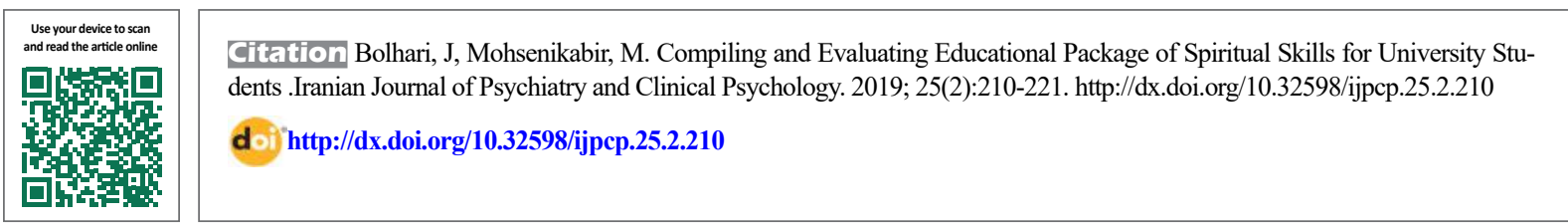

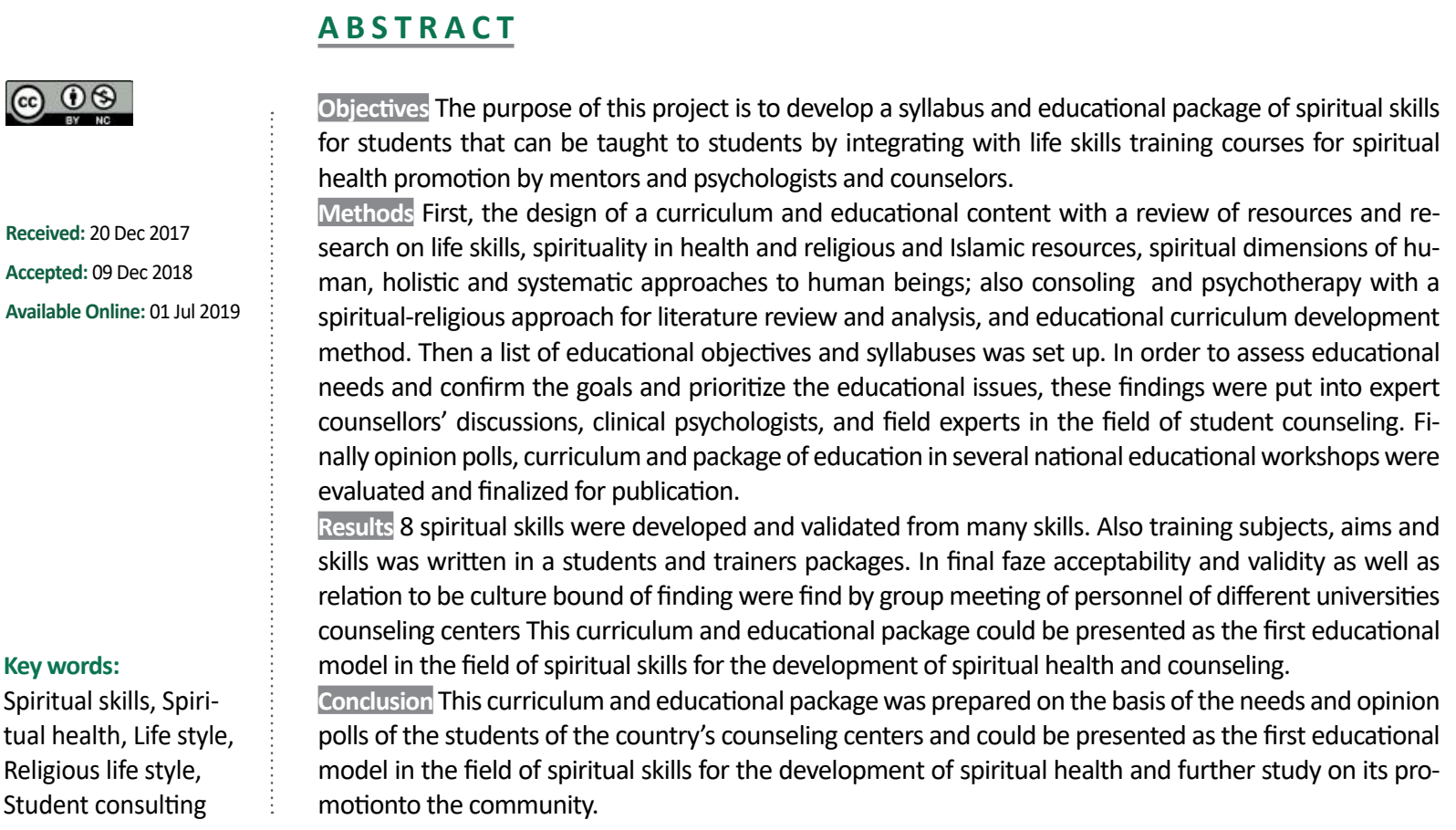

\section{Extended Abstract}

\section{Introduction}

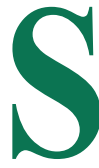

pirituality refers to the orientation or experience of a person in accordance with the attributes of the transcendental existence in the life. Research has shown that the spirituality and spiritual health affect the mental and physical health. With regard to the growing importance of the spirituality in science over the past few decades, and the spiritual health which is one of four human dimensions, i.e. biological, psychological, social and spiritual, the need for the use of the spiritual methods in taking care of health, training of spe-

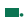

* Corresponding Author:

Masoomeh Mohsenikabir, PhD.

Address: Department of Health Psychology, Faculty of Psychology, Karaj Branch, Islamic Azad University, Karaj, Iran.

Tel: +98 (21) 4148632

E-mail: mmkmohseni@gmail.com 
cialized staff and assistance in the provision of the familial and social health has been emphasized. While training the life skills and healthy lifestyle are highly recommended by the global credible organizations such as UNICEF and the World Health Organization (WHO), and this skill training has developed a lot in the country, there is no familiarity and valid research about the spiritual skills in the country yet, and training the religious-spiritual skills are given only to the religious and spiritual centers. One of the reasons of this shortcoming is the lack of a manual and a scientific and systematic educational model in the spiritual skills training. The purpose of this applied research proposal was to design and compile an educational package of the spiritual skills for students to use the educational headings and textbooks as a model in the field of spiritual skills. This educational package, similar to the workshops for the life skills training, could be taught to the educators and students.

\section{Method}

Curriculum development was conducted in several stages, using various methods in needs and curriculum development in this research by educational research method, as following: First, by reviewing available findings in spiritual skills training, resources on lifestyle and healthy living skills teachings and recommendations in religious-Islamic and spiritual counselling literature and psychotherapy, and reviewing evidence in printed documents like books, encyclopedias, medical and humanities Persian articles databases, Google Scholar, Medline, psych lit, were searched and more than 31 religious-spiritual skills and their prioritization were obtained. Next, in order to complete findings by workshop qualitative method and group discussion, besides expert committee members, approximately 31 faculty members in different humanities fields, counsellors and psychotherapists, and students (in Zahedan), males and females, Shia and Sunni, were conducted by seminary and university studies, group needs assessment, and prioritizing and determining curriculum. In this way, out of 31 skills in pre-phase, 11 skills were selected by participants and experts, and the rest were removed or for next programs. The workshop was then summarized by research group members; headings, content, attitude-cognitive and skillful goals were finalized, and eight skills were proposed to curriculum development. Then, research history and related documentation were provided to experts consisting of psychiatrists and psychologists, and two textbooks preliminary draft were compiled for educators and students. Finally, headings and curriculum were taught to educators and students in three provinces workshops (Shiraz, Tehran, and Rasht). Curriculum content, and method or model were qualitatively evaluated, finalized, and introduced to Science Ministry to print.

\section{Results}

The first finding of the research was the lack of a guideline, a manual, and a scientific and systematic educational model in the training of the spiritual skills as the headings and techniques in the humanities field of the clinical psychology, counseling, and health psychology. In Persian and Latin sources, there were no well-documented articles with the exception of the religious writings or books without observing the scientific methodology in teaching the life skills and the spiritual skills, which could be a valuable finding for the importance of this study and the future suggestions.

In order to the compilation of an educational book based on the research review of the literature and the point of view of the experts as well as in the consultative workshops, at first, 31 religious and spiritual skills were chosen, and then, eight needs and skills were selected. The participants in this advisory workshop emphasized the systematic model of the spiritual cognition, comprehensive, non-biased, non-related to the religion and Islam, which has a sense of non-scientific bias. These eight headings of the educational texts and the spiritual skills were as following: 1. what is the spirituality 2 . The life skills is based on the spiritual skills 3 . The spiritual approach in the medical education and humanities 4. The religious and spiritual counseling and psychotherapy 5. The spiritual self-awareness skills 6 . The problem solving with the spiritual approach. 7. The forgiveness skills in the restoration of the relationships. 8. The rosary as a spiritual skill.

\section{Discussion}

For many students, having healthy life skills, especially in promoting values, commitment, and religious-spiritual dimensions is a major challenges of their lives. To define human dimensions, the WHO refers to physical, psychological, social and spiritual dimensions.

The result of this analysis is that a student needs a new life skills set in spiritual dimension to overcome routine stress and achieve a desirable life. Similarity of this package with other spiritual care packages is to define basic concepts like spirituality and religion definition, reasons and evaluation. But the difference is to introduce several spiritual skills, which can be taught along with life skills, which individuals apply in their daily lives. This is an innovation. This particular prominence of this research becomes clearer when it appears in research history used in research and available spiritual skills curriculum, or in centers and religious people and seminary, or to psychotherapy and counseling patients if it is specialized and scientific. Although this study and educational model have been accepted and validated with sev- 
eral assessments, further research is recommended on these skills effects. Another finding was the emphasis of spiritual skill trainers on how to train these skills, like counseling and psychotherapy, methodically, comprehensively, nonbiased, non-related to the religion and Islam, and in clinical area. Therefore, the important point after presentation of this research finding is that individual's mental disorders are required to be treated by skilled counselors and psychiatrists, and their religious teachings are to be conducted by teachers, clerics, preachers, and religious missionaries.

\section{Ethical Considerations}

Compliance with ethical guidelines

According to the ethics committee of Iran university of Medical Sciences, interviews with individual could be made if they were satisfied. Participants could withdraw from the research if they didn't want it. The cases in which the participants name was registered for training was classified as confidential.

\section{Funding}

This study was financially supported by the Ministry of Science, Research and Technology and Counseling Center. A technical support also received from, School of Behavioral Sciences and Mental Health of Iran University of Medical Sciences, Spiritual Health Research Center, Mental Health Research Center, and especially Student Consultation Center of Tehran University.

\section{Author's contributions}

Conceptualization: Both authors; Methodology: Jafar Bolhari; Validation: Jaafar Bolhari; Investigation: Both authors; Sources: Masoomeh Mohseni Kabir; Writing - Original Draft Preparation: Masoomeh Mohseni Kabir; Writing Review \& Editing: Jaafar Boalhari; Project Administration: Jaafar Bolhari.

\section{Conflicts of interest}

The authors declared no conflict of interest.

\section{Acknowledgements}

The authors would like to thank the centers and authorities supported this study including Dr. Hamid Yaqoubi, Hamid Peyrovi, Bagher Ghobari Bonab, Robabeh Nouri Ghasemabadi, Moslem Mirzaei, Zeinab Ghaempanah, Dr. Shahrbanoo Ghahari, Dr. Hoda Dosalivand, and Elham Zareidoust. 


\title{
طراحى و ارزشيابى بسته آموزشى مهارتهاى معنوى براى دانشجويان
}

\author{
دكتر جعفر بوالمرى' هـ، "معصومه محسنى كبير' 'ه \\ ا- روانيز شك، دانشكده علوم رفتارى و سلامت روان (انستيتو روانيزشكى تهران)، مركز تحقيقات سلامت معنوى، دانشكاه علوم بزشكى ايران، تمهران، ايران.

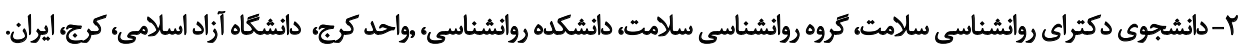

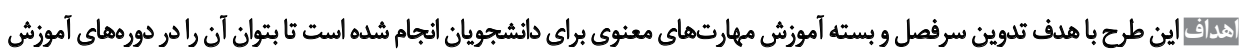

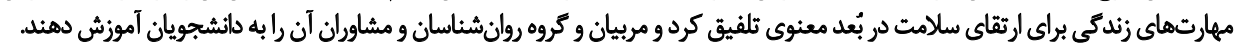

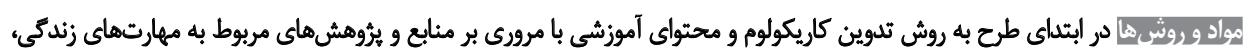

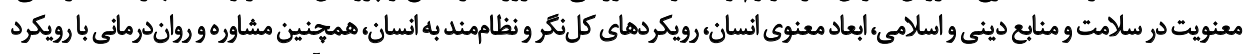

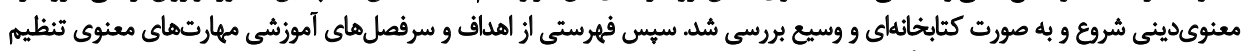

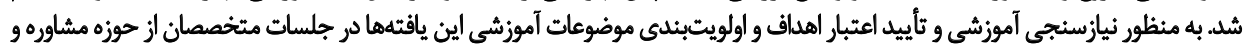

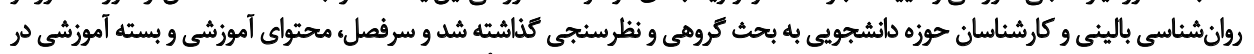

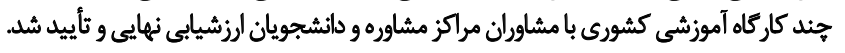

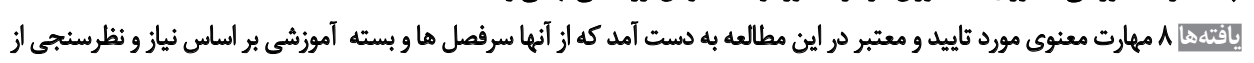

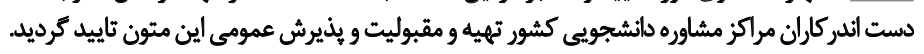

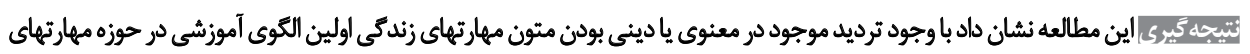

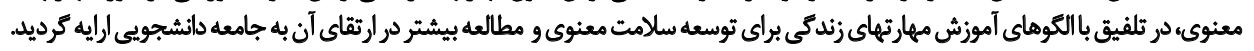

حكيد

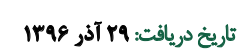

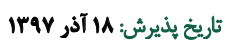

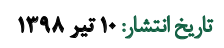

تعريف برخى از يُروهشغران كشور معنويت يعنى بُعد والاى

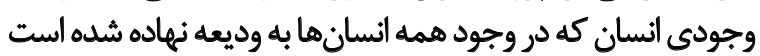

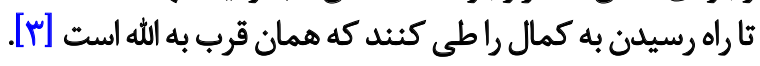
دين و معنويت كاهى به نوعى به جاى هم به كار مىروند. وازه دين در انكليسى از كلمه ريلاجيو به معناى بلهمبـيست

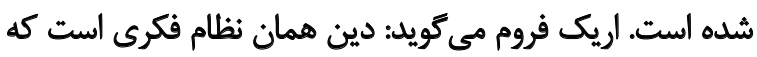

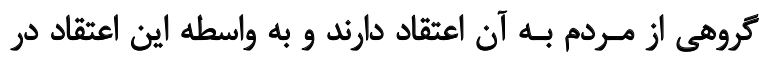

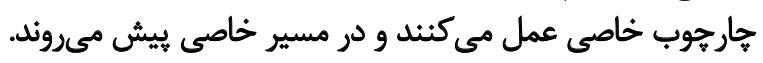

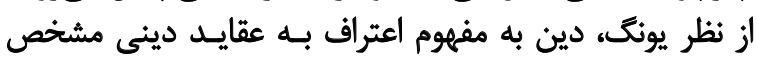

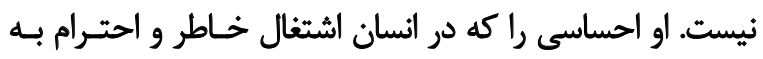
يك ذات مافوق ايجاد مي كند، دين ناميده است.

اينكونه تبيين از دين، نزديكى زيادى به باورهاى مرتضى مطهرى

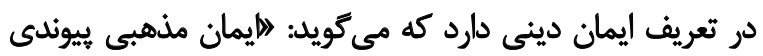

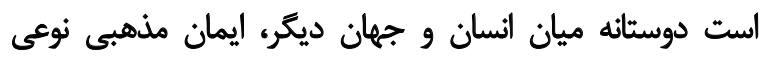

daleo

وازٔه معنويت در انظيسى از ريشه لاتين اسيريتوس كرفته شده

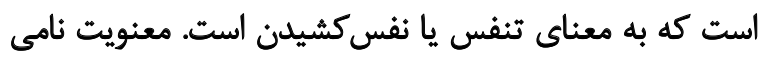

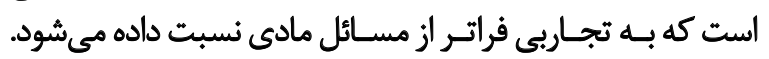

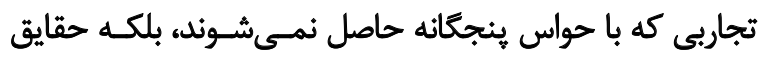

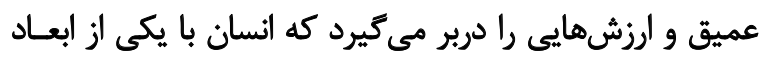

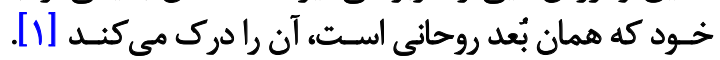
آبراهام مازلو'، از روانشناسان بيرو مكتب انسانكرايى، به

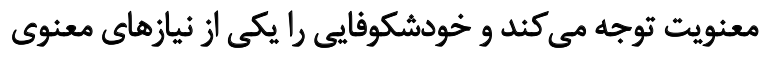

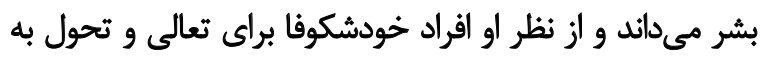

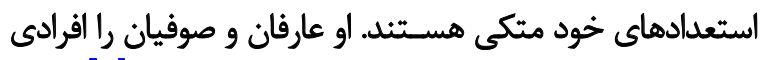

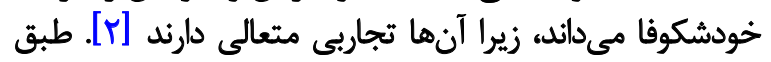

1. Abraham Maslow

$$
\begin{aligned}
& \text { * نويسنده مسئول: } \\
& \text { معصومه محسنى كبير }
\end{aligned}
$$

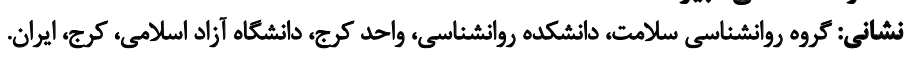

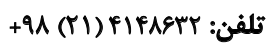

$$
\begin{aligned}
& \text { يست الكترونيكي: mmohoni@gmail.com }
\end{aligned}
$$




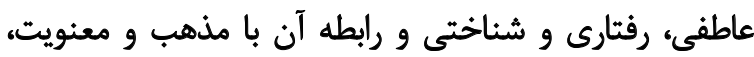

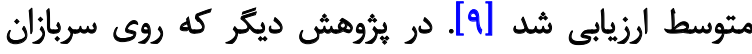

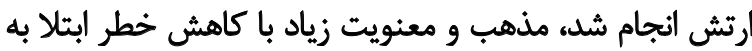

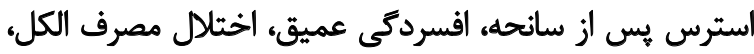

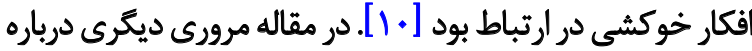

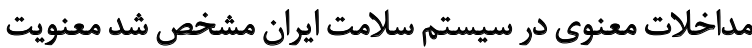

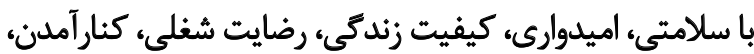

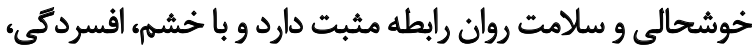

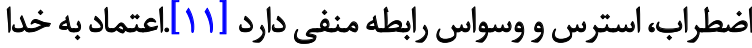

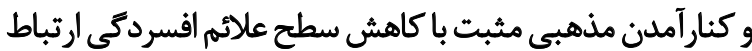

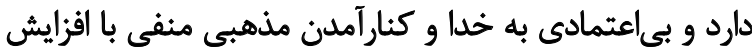

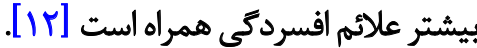

در تحقيقات ديكر مذهب با سطح بايينتر ناراحتى رواني،

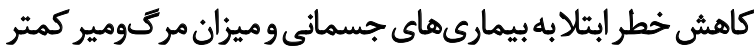

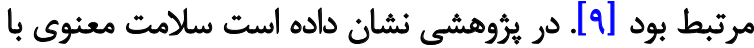

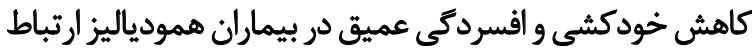

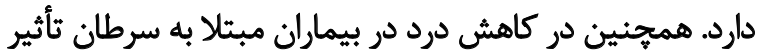

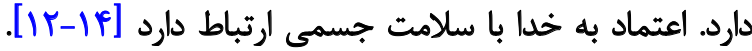

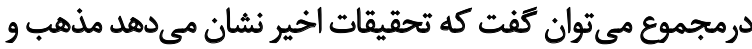

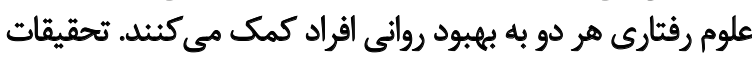

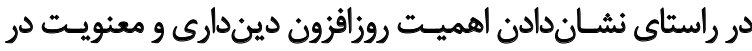

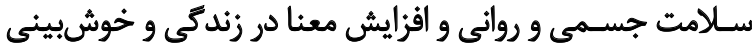

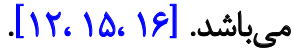

اهميت رشد معنوى در اين است كه در رشد و شكوفايى آن

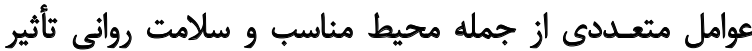

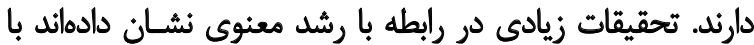

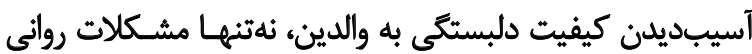

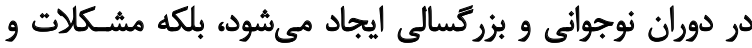

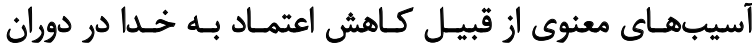

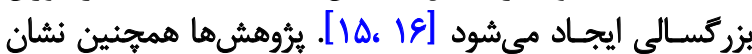

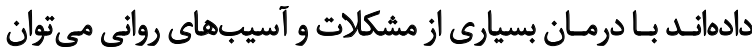

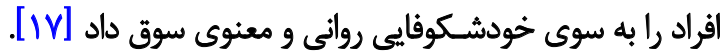

تعاريف متفاوتى از مهارتهاى زندكى را سازمان جهانى

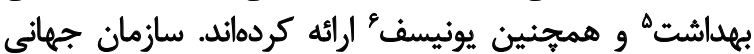

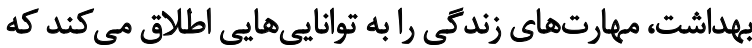

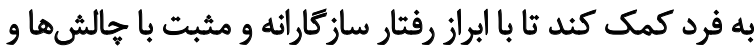

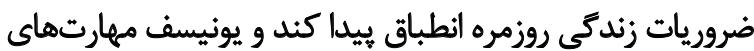

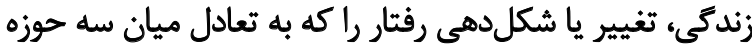

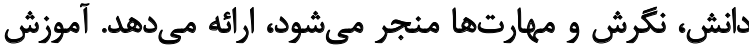

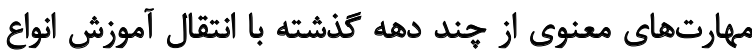

5. World Health Organization (WHO) 6. UNICEF
هماهنكى است بين انسان و آرمانهائكلى جهان. كوردون ويليام

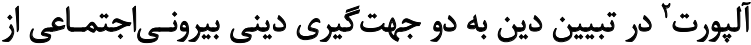

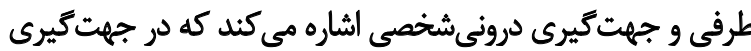

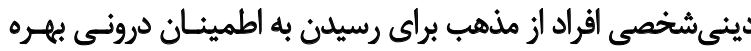

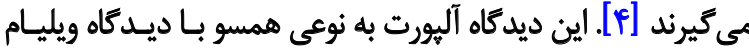

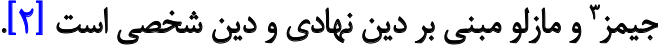

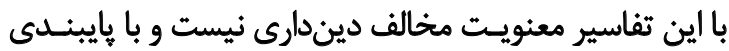

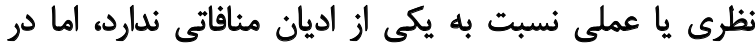

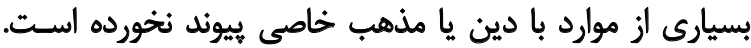

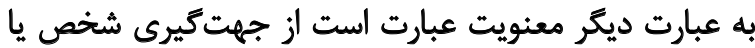

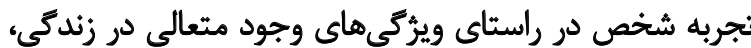

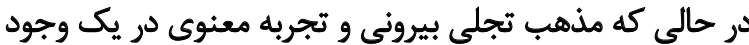

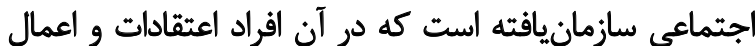

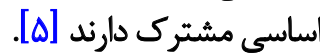

معنويت يك مفهوم عام است و مىتواند بيشتر جنبههاى

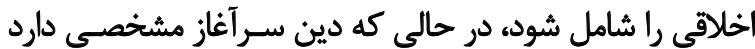

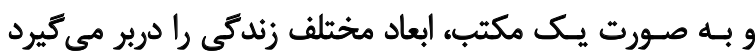

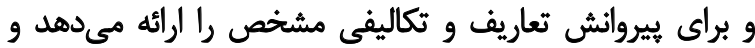

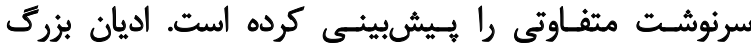

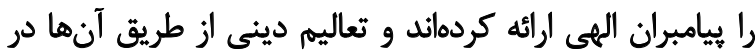

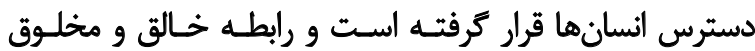
و جهان يس از مرك با جزئيات فراوان در تعاليم دينى عرضسه

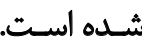

غبارى بناب معتقد است كه عشق و علاقه به انسانها،

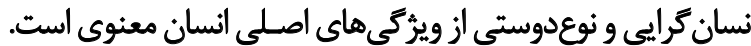

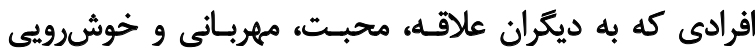

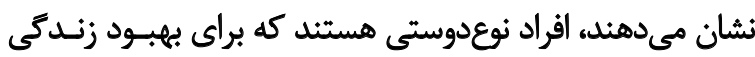

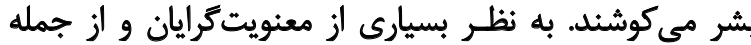

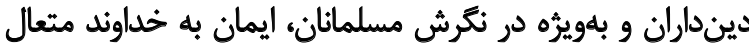

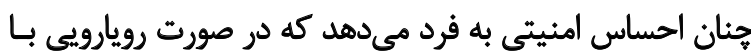

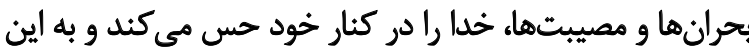

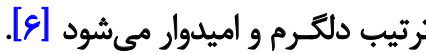

از جمله در قرآن كريم و در سوره حديد، آيه هب آمده است: الهمانا

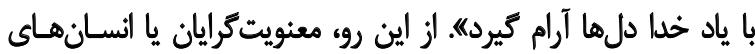

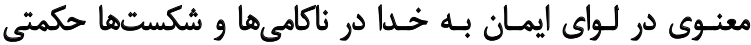

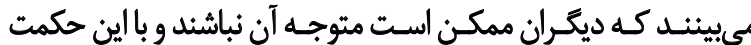

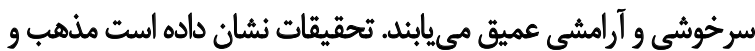

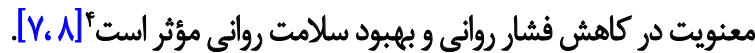
در يُروهشى مرورى سلامت روان به عنوان عملكردى از ابعاد

2. Gordon Willard Allport

3. William James

4. An Interview with Larry Dossy. "Tikkun 15(2000): 11-16. 
سلامت معنوى به روش مرور اسنادى دراسناد جائي مانئد كتاب،

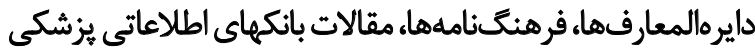

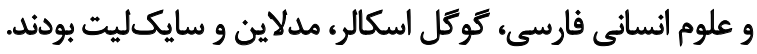

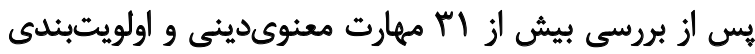

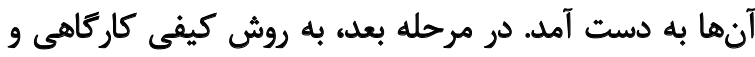

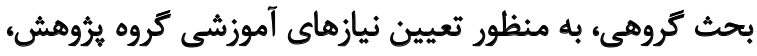

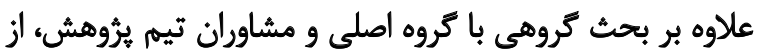

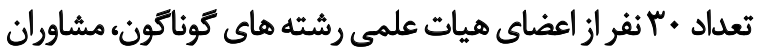

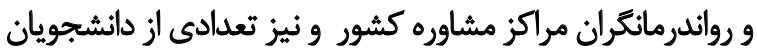

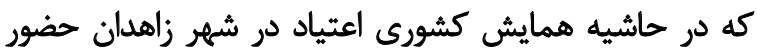

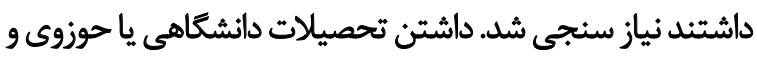

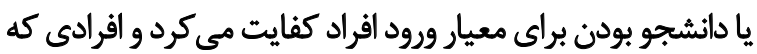

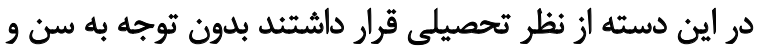

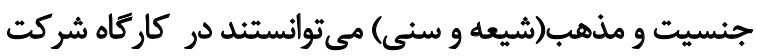

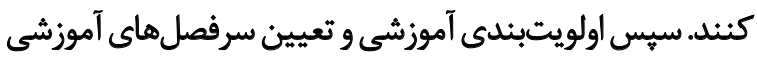

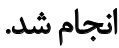

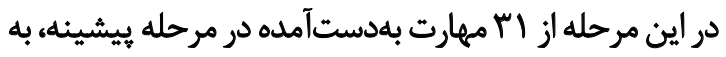

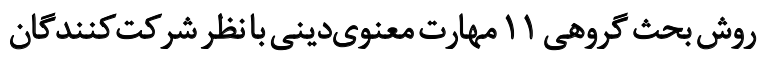

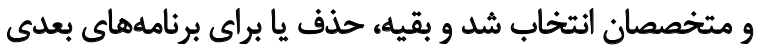

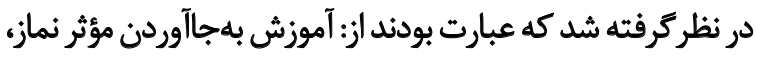

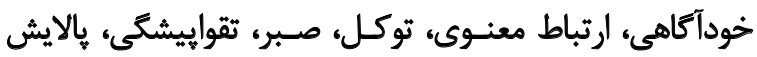

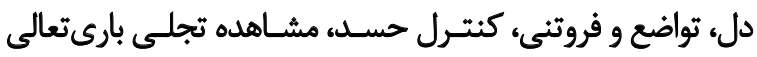

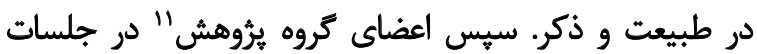

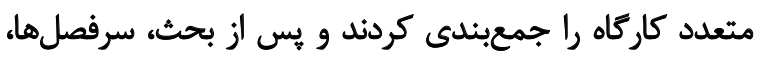

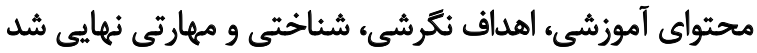

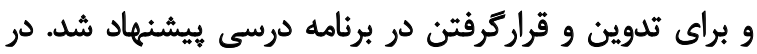

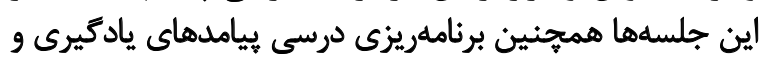

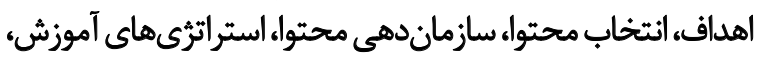

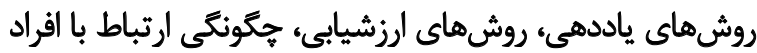

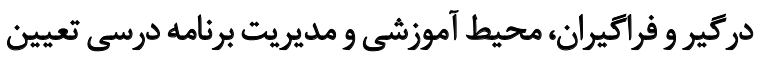

در مرحله بعدى ييشينه يُؤوهش و مستندات مرتبط در اختيار

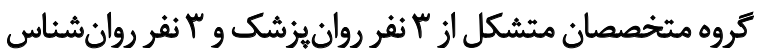

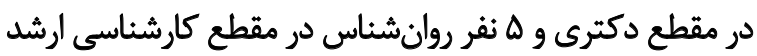

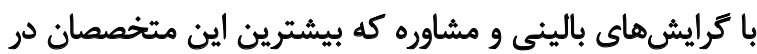

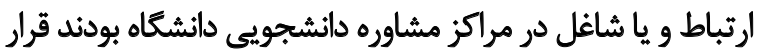

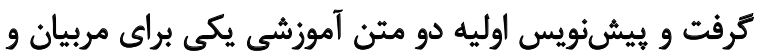

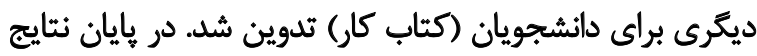

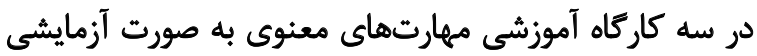

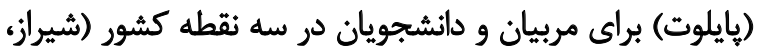

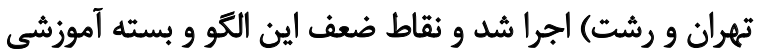
اصلاح و بسته آموزشى نهايى شد و و بقاط ضعف اين دفتر مركزى مشاوره

11. Experts committee

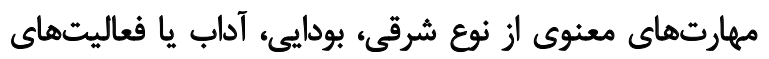

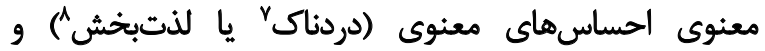

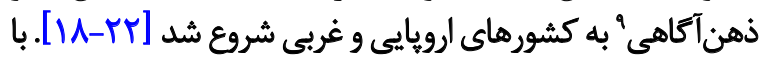

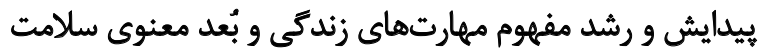

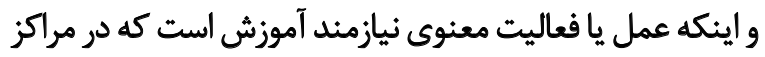

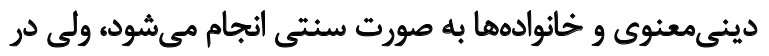

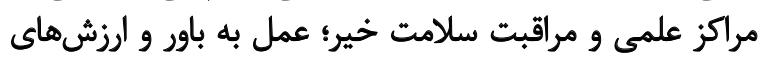

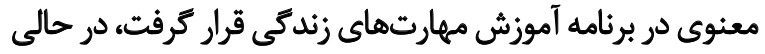

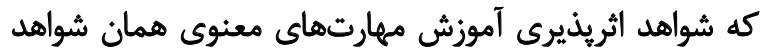

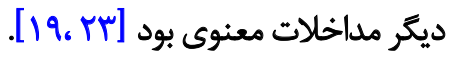

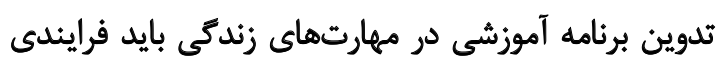

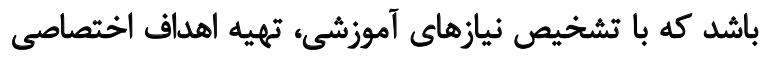

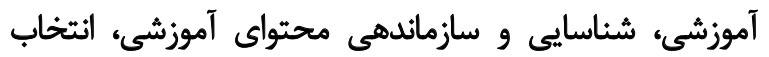

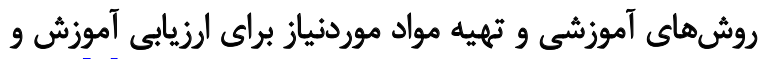

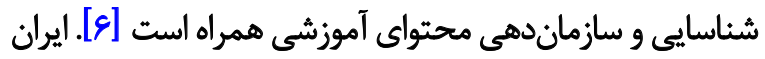

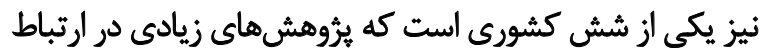

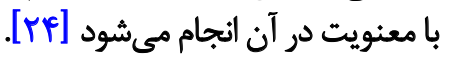

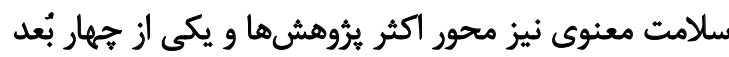

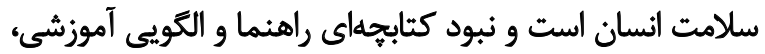

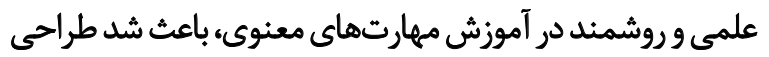

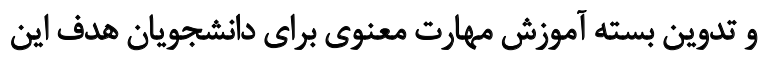

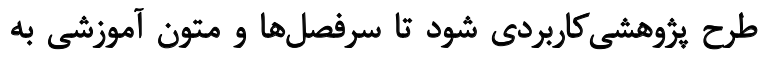

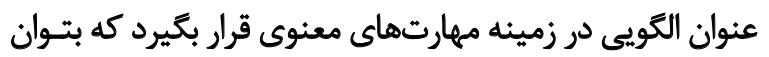

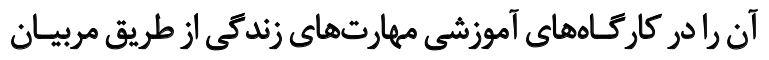

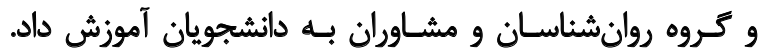

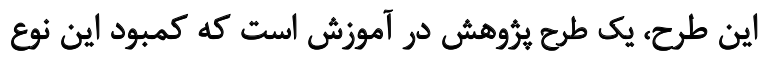
يزؤهش در كشور احساس مى شود.

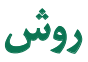

در اين يُوهش با استفاده از روش تدوين كاريكولوم" و برونامه

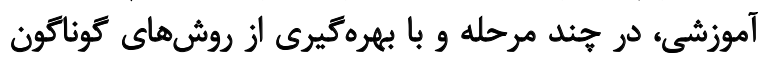

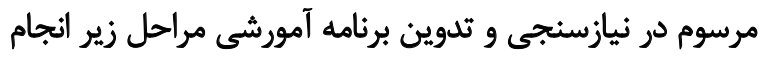

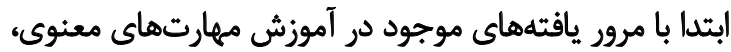

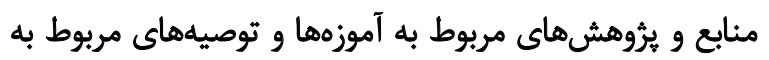

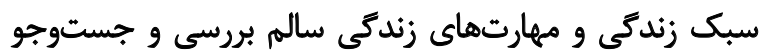

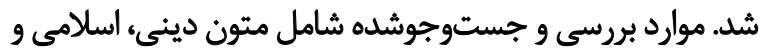

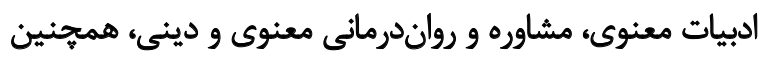

7. Painful spiritual feeling

8. Pleasant spiritual feeling

9. Mindfulness,

10. Curriculum development 
جدول ا. سرفصل هاى آموزشى مهارتهاى معنوى براى كليه دانشجويان مراجعه كنيده به مراكز مشاوره دانشجويى دانشكاههاى وزارت علوم با اهداف آموزشى

\begin{tabular}{|c|c|c|}
\hline اهداف آموزشى با برخى زيرعنوانها & سرفصل آموزشى كتاب & 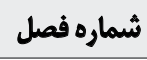 \\
\hline مفاهيم معنويت و ويثُكى هاى انسان معنوى، دين، هميوشانى معنويت بادين & معنويت جيست ؟ & 1 \\
\hline 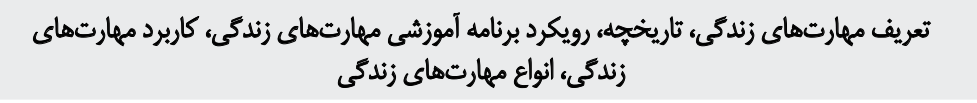 & مهارتهاى زندقى، يايله مهارتهاى & $r$ \\
\hline 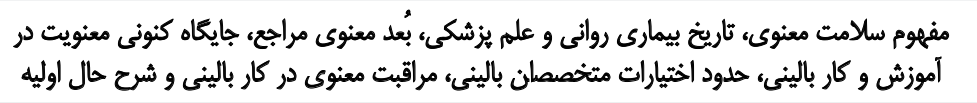 & رويكر معنوى در آموزش بزُشكى و علوم & r \\
\hline 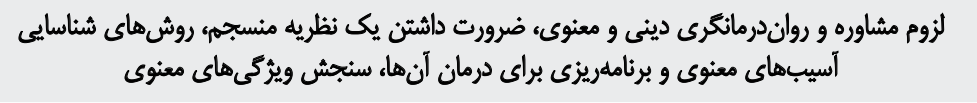 & مشاوره و رواندرمانكرى دينى و معنوى & p \\
\hline خودآكاهى، انواع خودآكاهى شامل خودآكاهى جسمى، خودآكاهم روانى، رابطه خودآكاهى با معنويت و & مهارتهاى خودآكاهى هعنوى & $\Delta$ \\
\hline 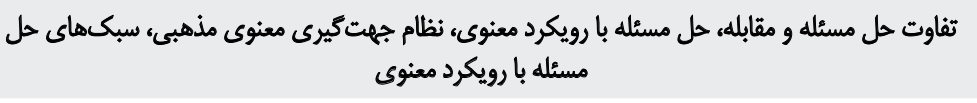 & حل مسثله بارويكرد معنوى & 8 \\
\hline تعريف بخشايشكرى، مفاهيم متفاوت با عفو و كذشته مبانى نظرى عفو و كنشت، مراحل بخشايشكرى، & مهارت بخشايشكرى در ترميم روابط & $\checkmark$ \\
\hline ذكر جيست؟ انواع ذكر، روش ذكر كفتن، مكان و زمان ذكر، مراتب ذكر، شرايط ذكر، آثار ذكر، موانع ذكر، & ذكر به عنوان يك مهارت معنوى & $\wedge$ \\
\hline
\end{tabular}

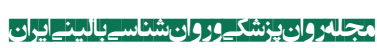

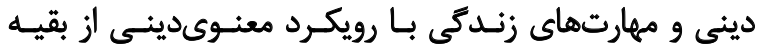
وزارت علوم و نيز براى هاٍ ارسال شد.

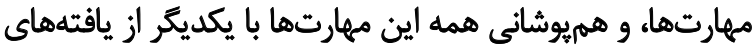

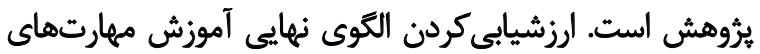

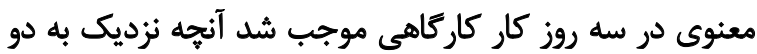

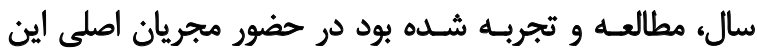

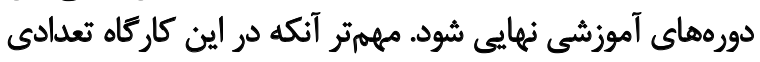

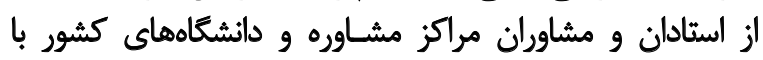

يافتهها

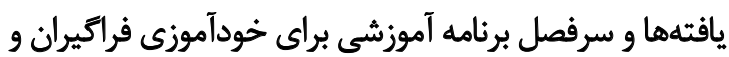

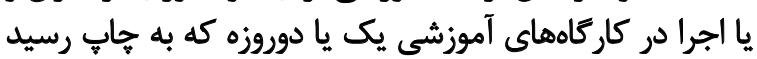
به اين ترتيب بود:

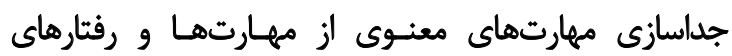
جدول r. برخى مهارتها و توانمندىهاى آموزشى

\begin{tabular}{|c|c|c|}
\hline 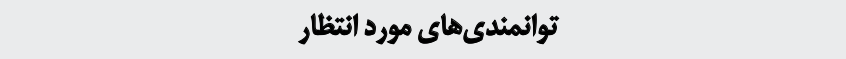 & 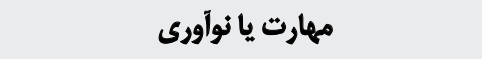 & شماره \\
\hline آكاهى از رويكرد و برنامه آموزش مهارتهاى زندكى، و جكونكى بكاركيرى مهارتها & مهارتهاي زئدىى، يايه مهارتشهاى معنوى، & 1 \\
\hline ارتباط و شح حال معنوى، مراقبتهاى معنوى در كار بالينى و مشاوره از ديدكاه اسلامى & تمرين مهارت معنوى در آموزش يزشكى و مشاوره & r \\
\hline دستيابى به مهارتهاى خودآكاهى معنوى، تمرين أتها ، أموزش به ديكران & مهارتهاى خودآكاهي معنوى & r \\
\hline آشنائي با مفهوم مساله و حل مساله و فرايندها، تمرين اثواع سبكهاي حل مساله با رويكرد & حل مسثله با رويكرد معنوى & f \\
\hline آشناييى و تمرين مهارت بخشايشكرى، ديدكاه ان رايت و الكوها و تفكر اسلامى & بخششايشكرى در ترمييم روابط & $\Delta$ \\
\hline شناخت و تمرين انواع ذكر و نمونه هايع از ذكرهـا & 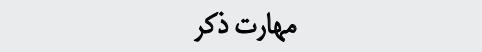 & 8 \\
\hline
\end{tabular}


نتيجه جنين رويكرد جندبعدى (يناي اين خواهد بود كه اين باور

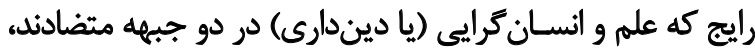

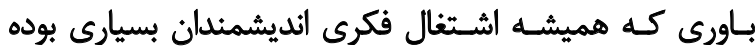

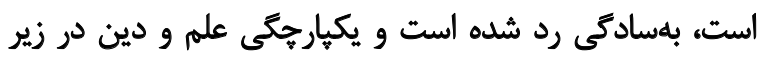

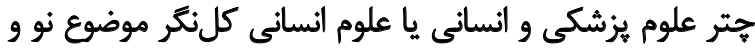

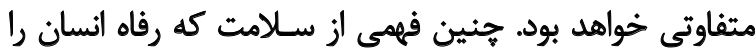

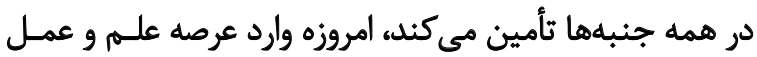

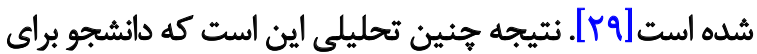

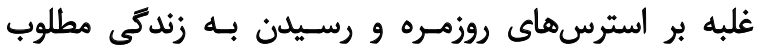

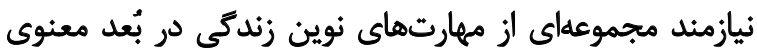

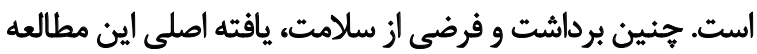

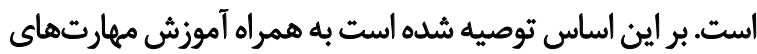

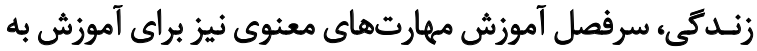

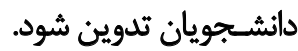

بخشش يكى از يافتههاى اين يُروهش است كه در سرفصل

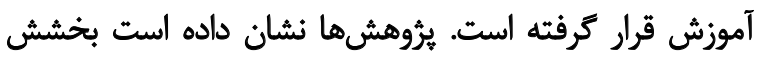

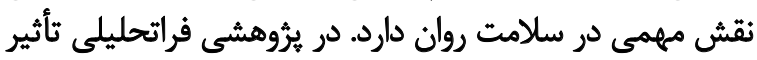

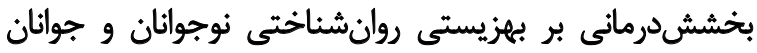

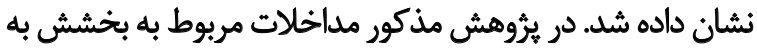

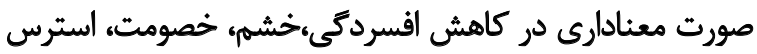

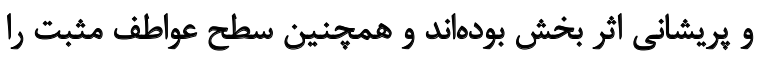

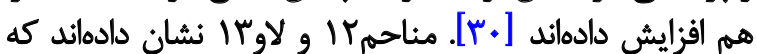

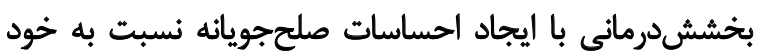

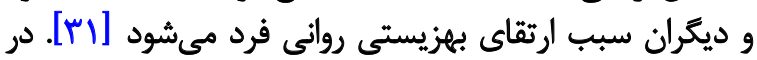

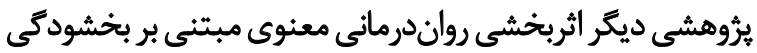

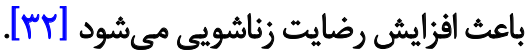

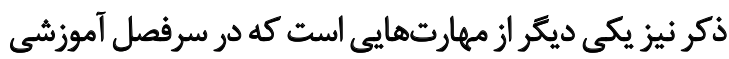

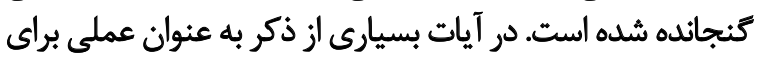

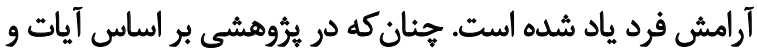

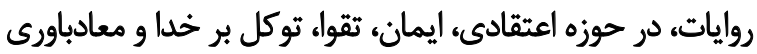

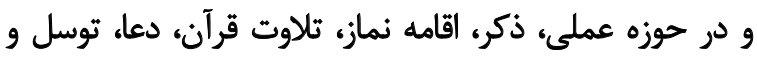

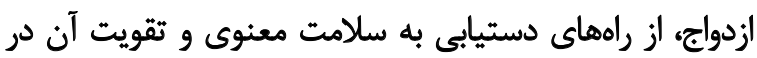

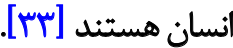

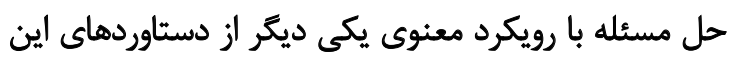

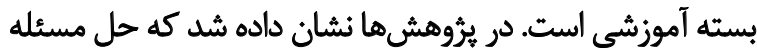

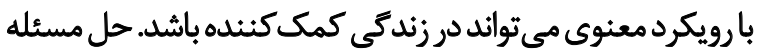

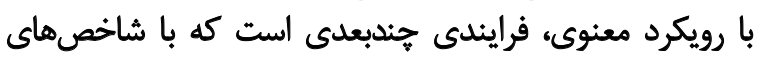

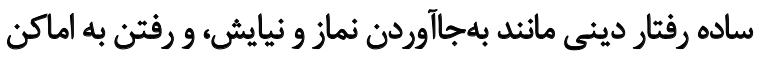

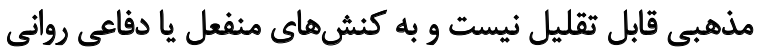

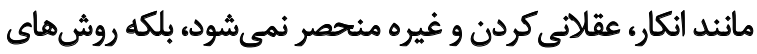

Sam Menahem .12 Melanie Love .13

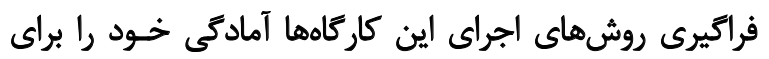

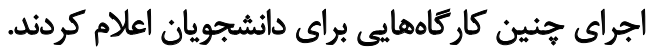

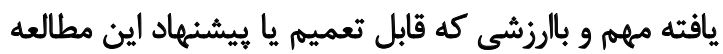

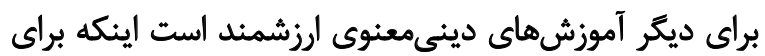

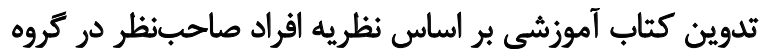

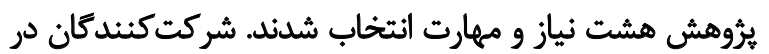

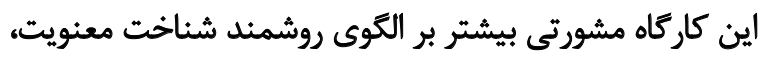

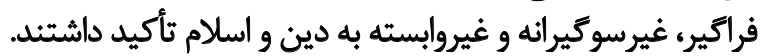

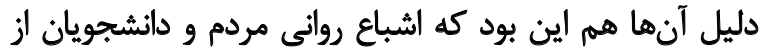

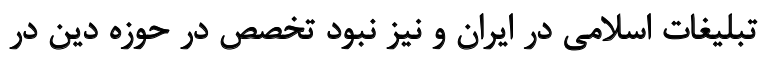

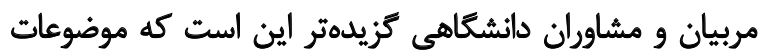

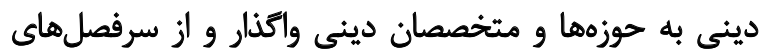
آموزشى حذف شود.

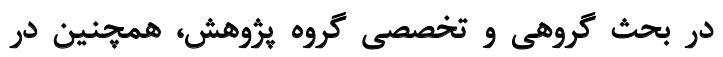

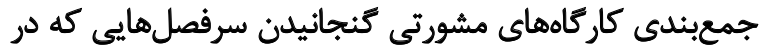

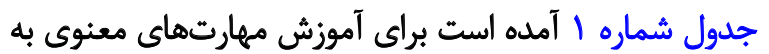

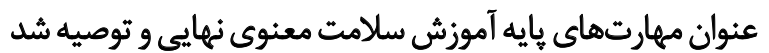

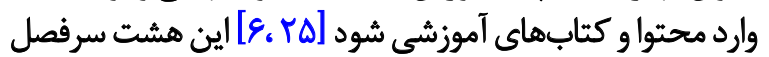

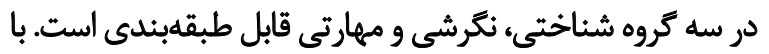

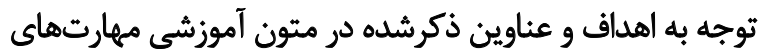

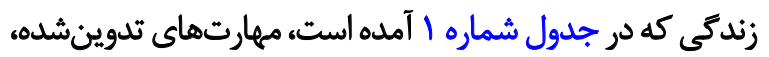

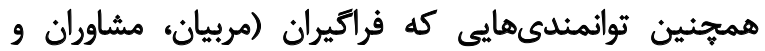

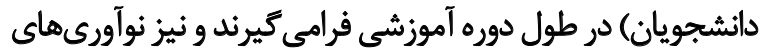

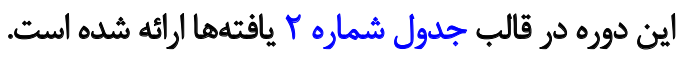

خلاصه يافتهها اين است كه براى ياسخكويى به نيازهاى

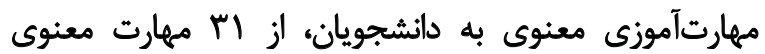

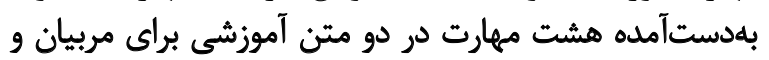

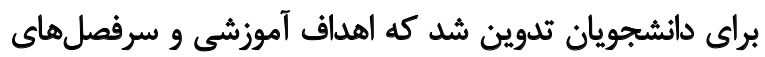

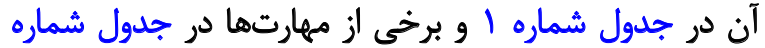

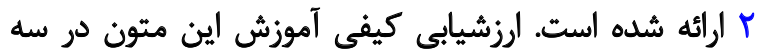

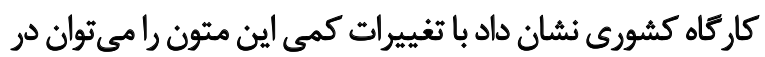
دانشكاههاى كشور آموزش داد داد.

بحث براي بسـيارى از دانشجويان، داشتن مهارتهاى سـالم زيسـتن،

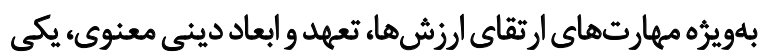

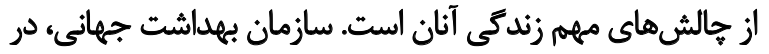

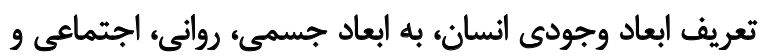

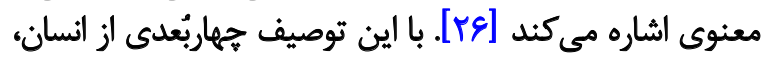

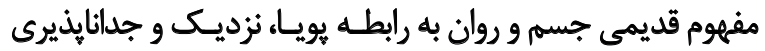

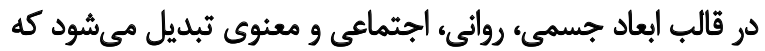

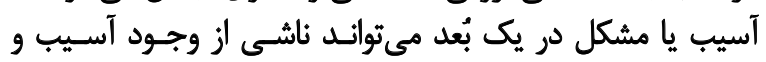

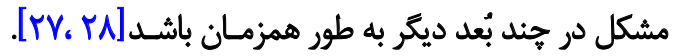


ايران؟ دانشكده علوم رفتارى و سلامت روان (انستيتو روانيزشكيى

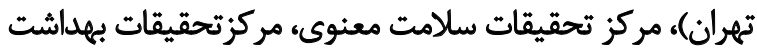

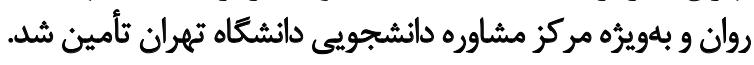

$$
\text { مشاركت نويسندكان }
$$

مفهوم سازى: هر دو نويسنده؛ روش شناسى: جعفربوالمرىى

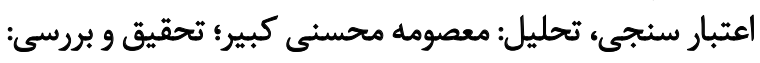

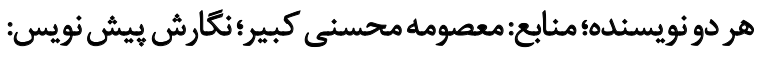

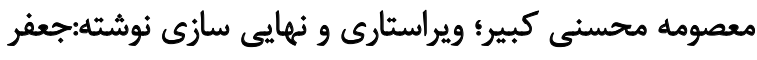

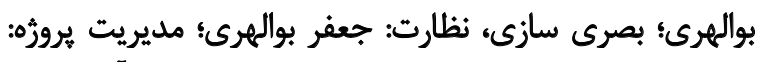

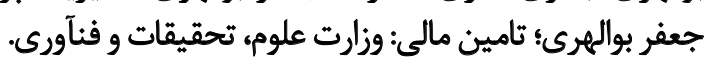

$$
\text { تعارض منافع }
$$

ونويسندكان هيجمَّونه تعارض منافع با سفارش دهنده برؤش

$$
\text { وحمايت كنيدكان ندارد }
$$

$$
\text { تشيكر و قادردافي }
$$

از مراكز حامى اين طرح و نيز از نمايندكان و همكاران آنها بانها

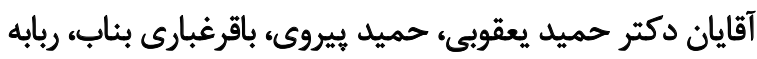

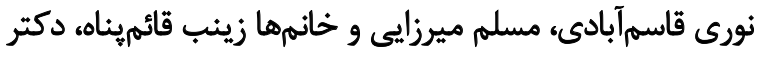

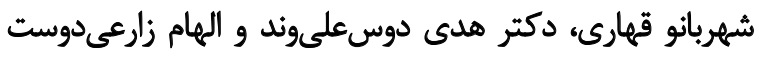
تشكر و قدردانى مي شئود.

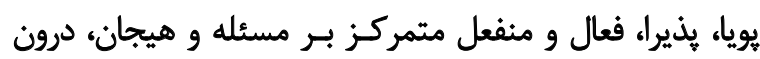

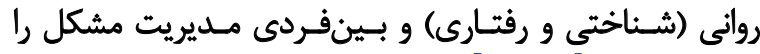

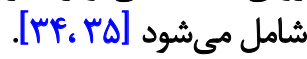

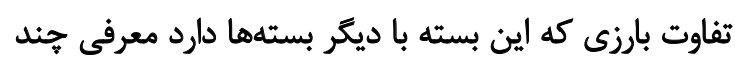

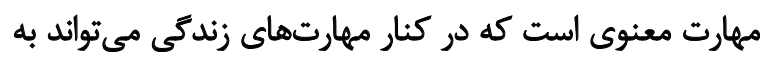

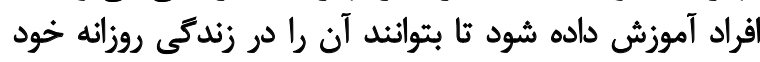

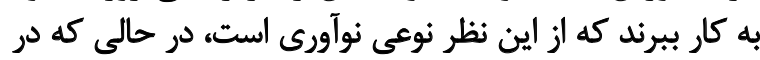

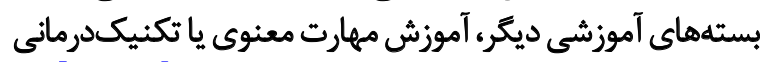

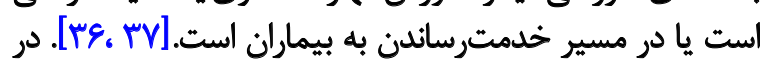

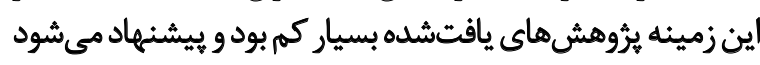
يرؤششهاى بيشترى در زمينه اثرات اين مهارتها ئها انجام كيرد.

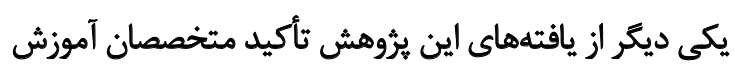

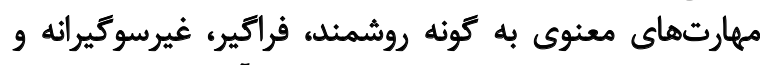

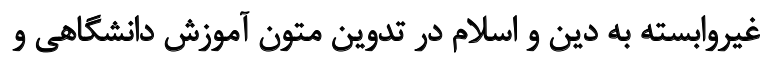

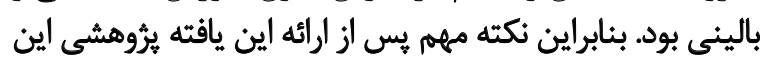

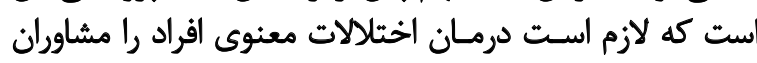

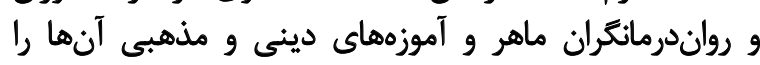
آموزكاران، روحانيان، واعظان و مبلغان دينى انجام دهند.

$$
\text { تئيجهيرى }
$$

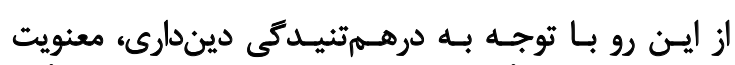

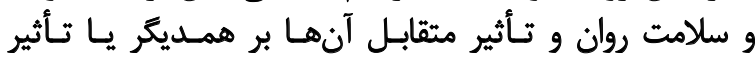

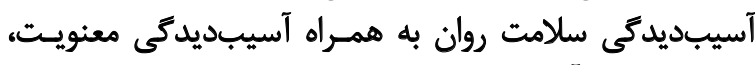

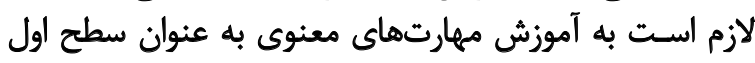

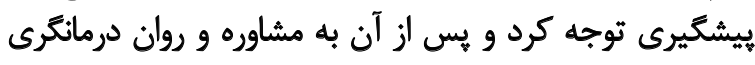

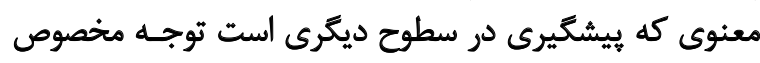

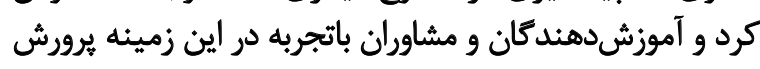

يابند.

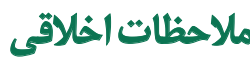

\section{بيروى از اصول الخلاق يُوهش}

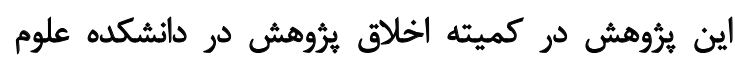

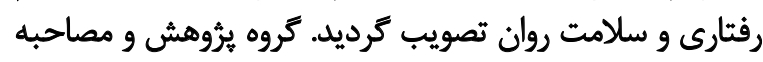

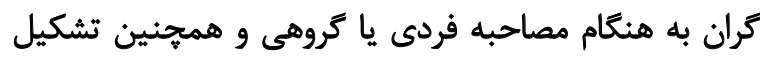

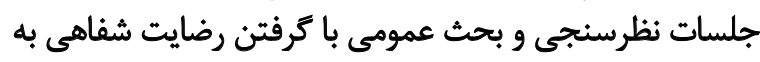

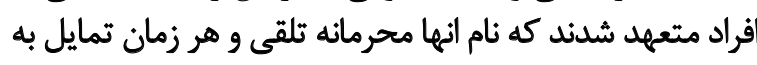

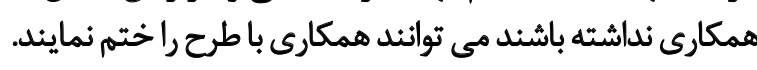

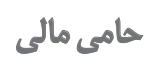

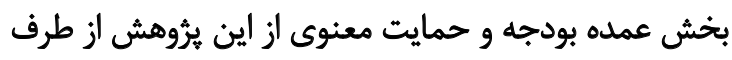

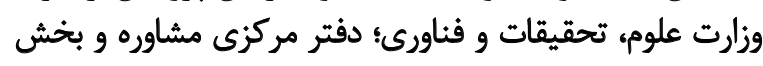

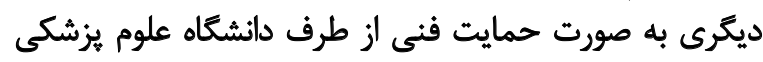




\section{References}

[1] Memaryan N, Rassouli M, Mehrabi M. Spirituality concept by health professionals in Iran: A qualitative study. EvidenceBased Complementary and Alternative Medicine. 2016; 1-9. [DOI:10.1155/2016/8913870] [PMID] [PMCID]

[2] Harpur T. The thinking person's guide to God: Overcoming the obstacles to belief. California: Prima Publishing; 1996.

[3] King P W. Climbing maslow's pyramid. Leicester: Troubadour Publishing Ltd; 2009.

[4] Allport G.W, Michel R J. Personal religious orientation and prejudice. Journal of Personality and Social Psychology. 1967; 5(4):432-8. [DOI:10.1037/h0021212] [PMID]

[5] Harris AHS, Thoresen C.E. Mccullough M.E, larson D B. Spirituality and religiosity oriented health intervention. Journal of Heath Psycology. 1999; 4(3):413-33. [DOI:10.1177/135910539900400309] [PMID]

[6] Gobari,B. [Consulting and psychotherapy with spiritual approach (Persian)]. Tehran: Counselling Center of University of Tehran; 2006.

[7] Ahmadi A, Shahmohammadi N. Studying the relationship between mental health, spirituality and religion in female students of, South Branch, Tehran Azad University. Procedia-Social and Behavioral Sciences. 2015; 205(2015):236-41.

[8] Sharma V, Marin DB, Koenig HK, Feder A, Iacoviello BM, Southwick SM, et al. Religion, spirituality and mental health of US military veterans: Results from the National Health and Resilience in Veterans Study. Journal of Affective Disorders. 2017; 217: 197-204. [DOI:10.1016/j.jad.2017.03.071] [PMID]

[9] Salsman JM, Pustejovsky JE, Jim HS, Munoz AR, Merluzzi TV, George L, et al. Meta-analytic approach to examining the correlation between religion/spirituality and mental health in cancer. Cancer. 2015; 121(21):3769-78. [DOI:10.1002/cncr.29350] [PMID] [PMCID]

[10] Hosseini M, Davidson P M. Fallahi Khoshknab M, Green A. Spiritual and religious interventions in health care: An integrative review. Iranian Rehabilitation Journal. 2013; 11(17):87-93.

[11] Krumre EJ, Pirutinsky S, Rosmarin DH. Jewish spirituality, depression, and health: An empirical test of a conceptual framework. International Journal of Behavioral Medicine. 2013; 20(3):327-36. [DOI:10.1007/s12529-012-9248-z] [PMID]

[12] Loureiro AC, de Rezende Coelho MC, Coutinho FB, Borges $\mathrm{LH}$, Lucchetti $\mathrm{G}$. The influence of spirituality and religiousness on suicide risk and mental health of patients undergoing hemodialysis. Comprehensive Psychiatry. 2018; 80:39-45. [DOI:10.1016/j. comppsych.2017.08.004] [PMID]

[13] Rippentrop AE, Altmaier EM, Chen JJ, Found EM, Keffala VJ. The relationship between religion/spirituality and physical health, mental health, and pain in a chronic pain population. Pain. 2005; 116(3):311-21. [DOI:10.1016/j.pain.2005.05.008] [PMID]

[14] Park CL, Paloutzian RF. Religion and meaning. Handbook of the Psychology of Religion and Spirituality. New York: Guilford Publications; 2014.

[15] Miller WR, Thoreson CE. Spiritulity, religion, and health: An emergeing research field. American Psychologist. 2003; 58(1):24-35. [DOI:10.1037/0003-066X.58.1.24] [PMID]
[16] Scott Richards P, Bergin AE. A spiritual strategy for counseling and, psychotherapy. Washington DC: American Psychological Association; 2005.

[17] Kirkpatrick LA. Attachment and religious representations and behavior. In: Cassidy J, Shaver PR. Handbook of attachment: Theory, research, and clinical applications. New York: Guilford Press; 1999.

[18] Hanh TN. The Miracle of mindfulness: An introduction to the practice of Meditation [Ho M, English Trans.]. Boston: Beacon Press; 1987.

[19] McCown D, Reibel D, Micozzi MS. Teaching Mindfulness: A clinical guide for clinicians and educators. New York: Springer; 2010. [DOI:10.1007/978-0-387-09484-7]

[20] Didonna F. Clinical Handbook of Mindfulness. Berlin: Springer; 2009. [DOI:10.1007/978-0-387-09593-6]

[21] Hefti R. Integrative religion and spirituality into mental health care, psychiatry and psychotherapy. Religions. 2011; 2(4):611-27. [DOI:10.3390/rel2040611]

[22] Addiss DG. Spiritual themes and challenges in global health. Journal of Medical Humanities. 2015; 39(3):337-48. [DOI:10.1007/ s10912-015-9378-9] [PMID] [PMCID]

[23] Bolhari J. Gobary Bonab B, Gahari SH, Mirzaee M, Ragebian $\mathrm{R}$, et al. [Spiritual Skills Training: A guidabook forl trainers (Persian)]. Tehran,: Ministry of Science Research and Technology/ The Councelling \& Health Office \& Counselling Center of University of Tehran; 2013.

[24] Lucchetti G, Lucchetti ALG. Spirituality, religion, and health: Over the last 15 years of field research (1999-2013). The International Journal of Psychiatry in Medicine. 2014; 48(3):199-215. [DOI:10.2190/PM.48.3.e] [PMID]

[25] Nouri R. Spiritual Skills Training: A workbook for university students (Persian)]. Tehran: Ministry of Science Research and Technology/The Councelling \& Health Office \& Counselling Center of University of Tehran; 2013.

[26] Hsiao YC, Chiang HY, Lee HC, Chen SH. The effects of a spiritual learning program on improving spiritual health and clinical practice stress among nursing students. The Journal of Nursing Research. 2012; 20(4):281-90. [DOI:10.1097/jnr.0b013e318273642f] [PMID]

[27] Moreira CN, Marques CB, Salomé GM, Cunha DR, Pinheiro FA. Health locus of control, spirituality and hope for healing in individuals with intestinal stoma. Journal of Coloproctology. 2016; 36(4):208-15. [DOI:10.1016/j.jcol.2016.04.013]

[28] Andrew M.M., Boyle JS. Transcultural Concepts in Nursing. London: Lippincott Company; 2003.

[29] Gordon J. Medical humanities: To cure sometimes, to relieve often, to comfort always. Medical Journal of Australia. 2005; 182(1):5-8.

[30] Akhtar S, Barlow J. Forgiveness Therapy for the Promotion of Mental Well-Being: A systematic review and metaanalysis. Trauma, Violence, \& Abuse. 2018; 19(1):107-22. [DOI:10.1177/1524838016637079] [PMID]

[31] Menahem S, Love M. Forgiveness in psychotherapy: The key to healing. Journal of Clinical Psychology. 2013; 69(8):829-35. [DOI:10.1002/jclp.22018] [PMID] 
[32] Ghafoori S, Mashhadi A, Hasanabadi H. [The effectiveness of spiritual psychotherapy based on forgiveness in order to increase marital satisfaction and prevent marital conflicts of couples in the city of Mashhad (Persian)]. Journal of Fundamentals of Mental Health, 2013; 15(57):45-57.

[33] Moaaref M, Asadi F. [The factors of achieving spiritual health from the perspective of the Qura and the Hadith (Persian)]. Quartery Journal of Islamic Insight and Education. 2017; 14(41):9-40

[34] Folkman S, Moskowitz JT. Coping: Pitfalls and promise. Annual Review of Psychology. 2004; 55(1):745-74. [DOI:10.1146/annurev.psych.55.090902.141456] [PMID]

[35] Harrison MO, Koenig HG, Hays JC, Eme-akwari AG, Pargament KL. The epidemiology of religious coping: A review of recent literature. Internatonal Review of Psychiatry. 2001; 13(2):8693. [DOI:10.1080/09540260120037317]

[36] Memaryan N, Nahardani SZ, Rassouli M, Vahidshahi K. [Developing educational goals and expected competencies for teaching spiritual health to the students of medical sciences (Persian)]. Iranian Journal of Medical Education. 2016; 17(12):116-25.

[37] Puchalaski CM, Blall B, Kogan M, Bulter A. Spirituality and health: The development of a field. Academic Medical. 2014; 89(1):10-6. [DOI:10.1097/ACM.0000000000000083] [PMID] 
This Page Intentionally Left Blank 